\title{
Endoscopic Submucosal Hydrodissection with Paradoxical Movement of the Colonoscope Using Hybrid Knife "Traction Mode" for Malignant Polyp in the Cecum
}

\author{
Felipe Ramos-Zabala ${ }^{1,2}$
}

1Department of Gastroenterology, HM Montepríncipe University Hospital, HM Hospitales Group, Boadilla del Monte, Madrid, Spain

${ }^{2}$ Department of Clinical Sciences, School of Medicine, University of CEU San Pablo, Boadilla del Monte, Madrid, Spain

\begin{abstract}
Address for correspondence Felipe Ramos-Zabala, MD, PhD, Departments of Gastroenterology and Clinical Sciences, HM Montepríncipe University Hospital, School of Medicine, University of CEU San Pablo, Av. de Montepríncipe, 25, 28660 Boadilla del Monte, Madrid, Spain (e-mail: framoshdiaz@gmail.com).
\end{abstract}

J Digest Endosc 2021;12:51-53.

\begin{abstract}
Keywords

- endoscopic submucosal dissection

- hybrid knife

- hydrodissection

- polyp

The water-jet hydro dissection technique has been shown to be effective for colorectal tumors. This case report illustrates type T hybrid knife for the elevation of the submucosal layer, cutting the mucosa and dissecting submucosal fibers. ESD was performed using ERBEJET 2 hydrodissection system and hybrid Knife. The resection was completed en bloc within 135 minutes without adverse events. Pathology examination revealed a well-differentiated adenocarcinoma confined to the shallow submucosal layer with free resection margins.
\end{abstract}

A 75-year-old patient who underwent colonoscopy that showed a cecal malignant polyp was referred to our hospital for right colectomy (-Fig. 1). Our multidisciplinary team decided to perform endoscopic submucosal dissection (ESD).

ESD was performed using ERBEJET 2 hydrodissection system and hybrid Knife (ERBE, Germany) (-video 1). The lesion was elevated using selective-regulation high-pressure water-jet method. ${ }^{1}$ Poor endoscopic operability due to paradoxical movements of the colonoscope resulted in poor vision of the submucosa layer to safely perform dissection. In these situations, the device is usually exchanged for another that facilitates the technique. ${ }^{2}$ However, we continued ESD using a type Thybrid knife in "traction mode" (-Fig. 2). With the use of this knife in an open position, it was possible to perform a T-tip dissection that enabled traction and cutting of the submucosal tissue, similar to HookKnife (Olympus, Japan). In this way, the colonoscope remained in a stable position and slow and delicate movements were performed at a distance by pulling the tissue toward the endoscope to perform the dissection. This technique enables clear vision of the lesion, improving the dissecting process at the level of the deep submucosal plane, including a perpendicular approach to the muscular layer, although it requires maximizing operator's vigilance. published online

December 16, 2020
DOI https://doi.org/

10.1055/s-0041-1726155 ISSN 0976-5042.
(C2020. Society of Gastrointestinal Endoscopy of India.

This is an open access article published by Thieme under the terms of the Creative Commons Attribution-NonDerivative-NonCommercial-License, permitting copying and reproduction so long as the original work is given appropriate credit. Contents may not be used for commercial purposes, or adapted, remixed, transformed or built upon. (https://creativecommons.org/licenses/by-nc-nd/4.0/).

Thieme Medical and Scientific Publishers Pvt. Ltd. A-12, 2nd Floor, Sector 2, Noida-201301 UP, India 


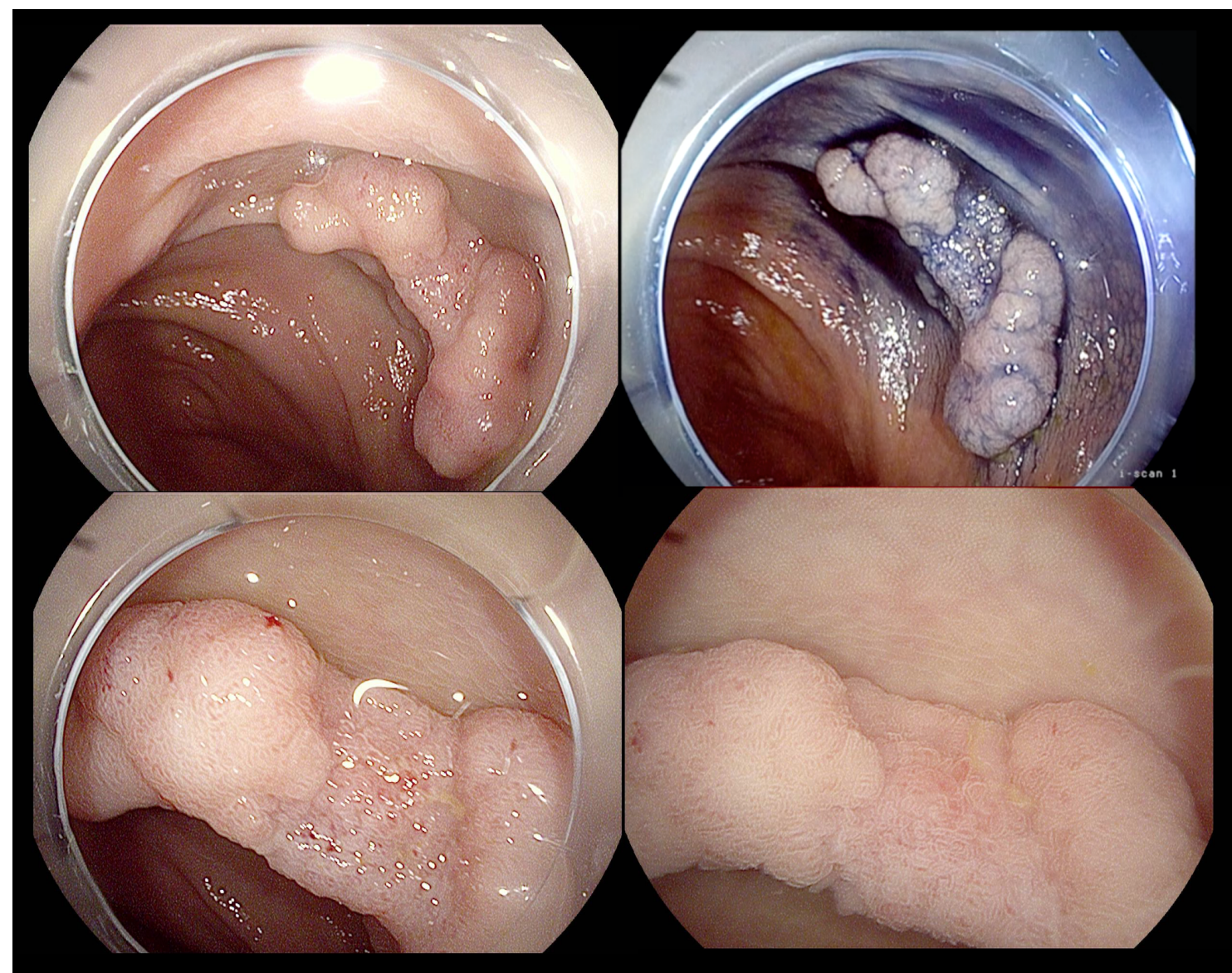

Fig. 1 Cecal polyp of $3 \mathrm{~cm}$ size with a demarcated central, showing suspicious pattern of submucosal invasion.

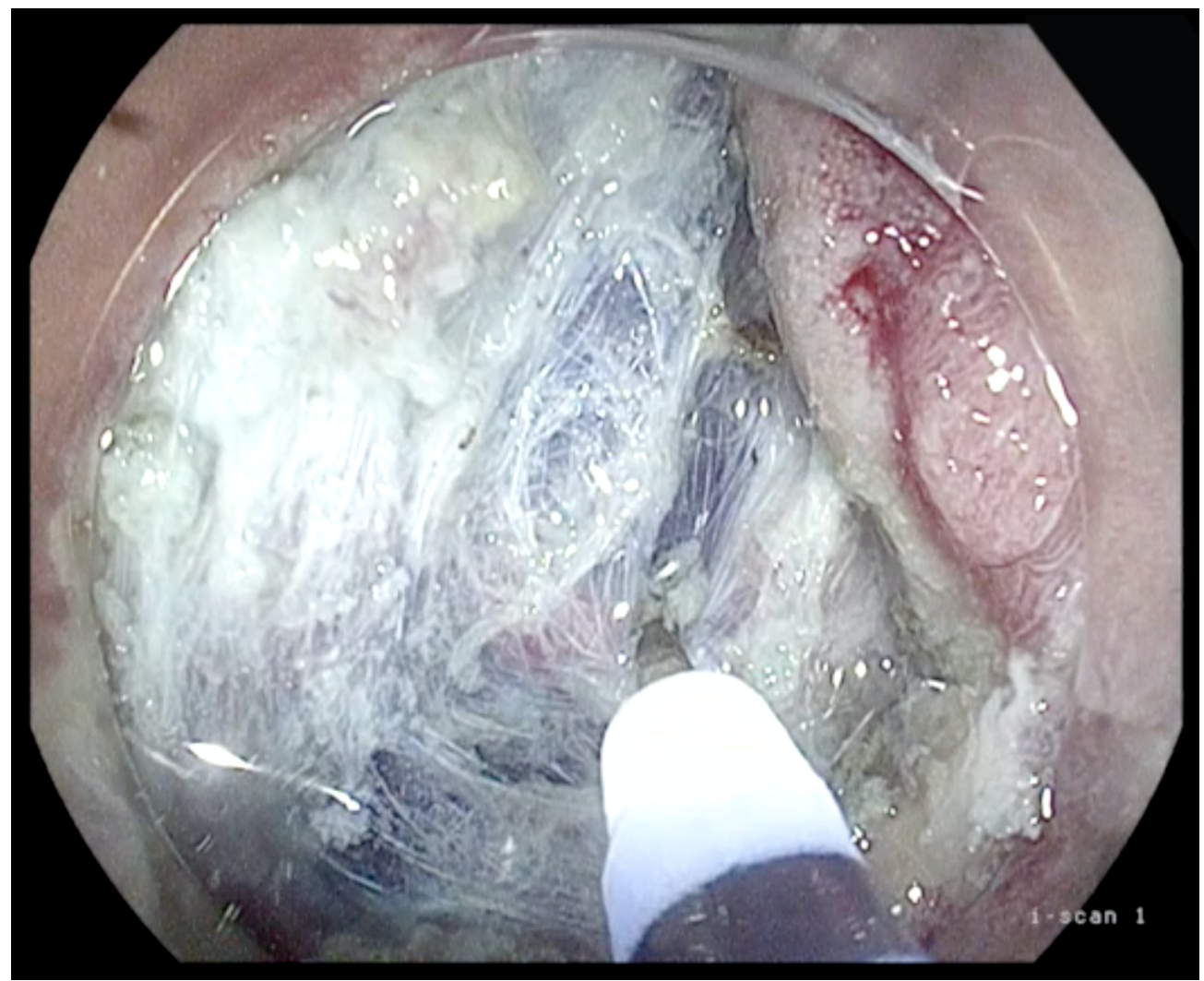

Fig. 2 Endoscopic submucosal hydrodissection using type T hybrid knife as "traction mode." 


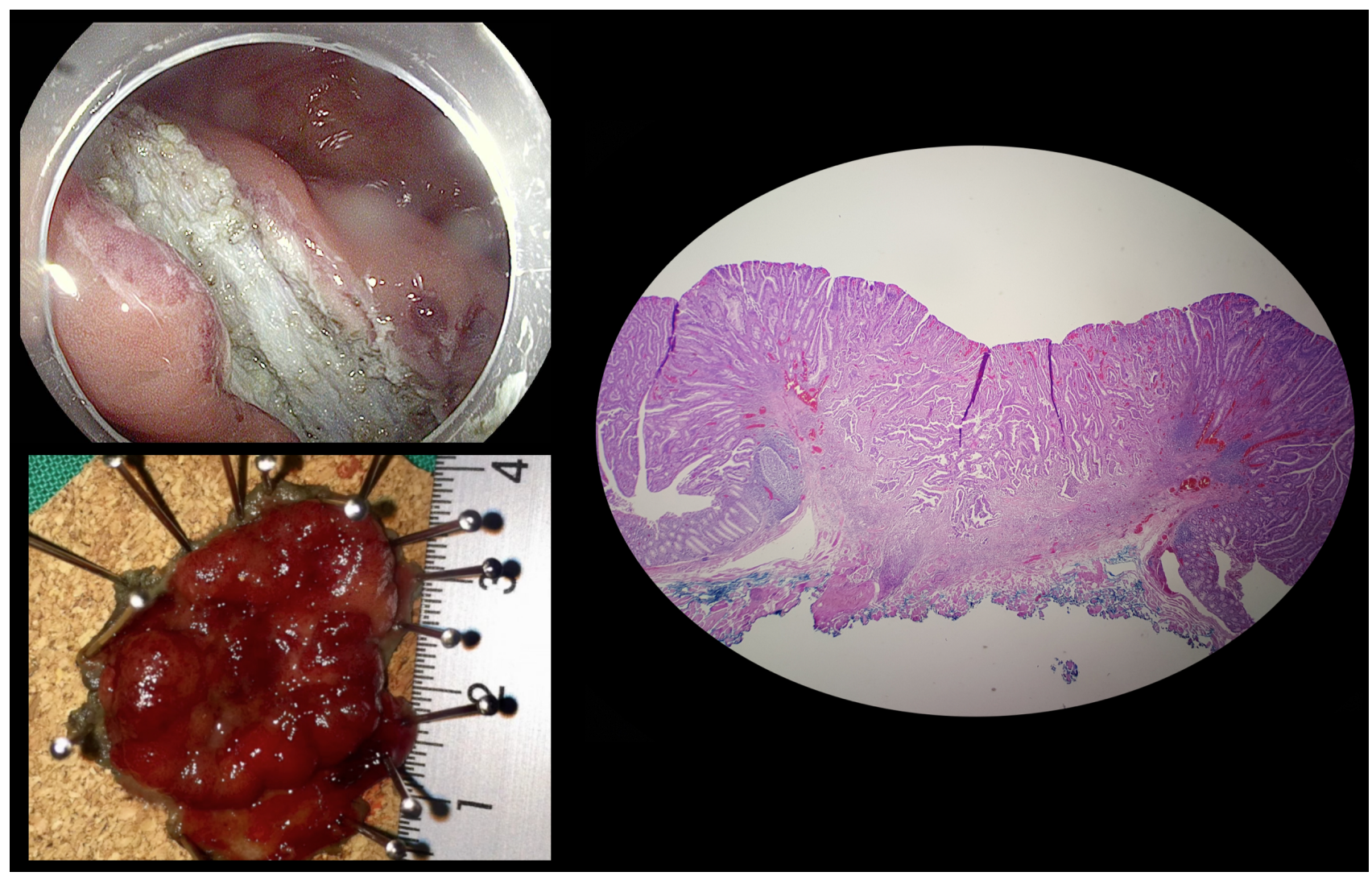

Fig. 3 Post procedure. (a) Resection surface. (b) Resected specimen after endoscopic dissection submucosal (c) Histological examination show a tubular adenoma with an area of well-differentiated adenocarcinoma confined to the shallow submucosal layer $(<1,000 \mu \mathrm{m})$ without evidence of lymphovascular or perineural invasion, absence of tumor budding, and free resection margins.

\section{Video 1}

Endoscopic submucosal hydrodissection with paradoxical movement of the colonoscope using hybrid knife in "traction mode" of a polyp with invasive submucosal carcinoma in the cecum. Online content including video sequences viewable at: https://www.thieme-connect. com/products/ejournals/html/10.1055/s-0041-1726155.

The resection was completed en bloc within 135 minutes

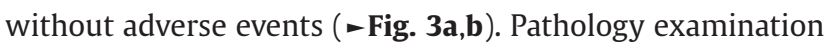
revealed a well-differentiated adenocarcinoma confined to the shallow submucosal layer with free resection margins (-Fig. 3c). Oncological and endoscopic follow-up was relapse-free after 48 months from ESD.

The water-jet hydrodissection technique has been shown to be effective for colorectal tumors., ${ }^{3,4}$ This case report illustrates that type T hybrid knife is a useful device not only for the elevation of the submucosal layer, cutting the mucosa, dissecting submucosal fibers and small vessels, or stopping bleeding but also for cutting with traction.

\section{Conflict of Interest}

None declared.

\section{References}

1 Ramos-Zabala F, Beg S, García-Mayor M, Parra-Blanco A, Moreno-Almazán L. Novel approach to endoscopic submucosal dissection of a cecal lesion with nonlifting sign by submucosal fatty tissue with use of selective-regulation high-pressure water-jet method and immersion in saline solution. VideoGIE 2020;5(3):116-119

2 Hayashi N, Tanaka S, Nishiyama S, et al. Predictors of incomplete resection and perforation associated with endoscopic submucosal dissection for colorectal tumors. Gastrointest Endosc 2014;79(3):427-435

3 Ramos-Zabala F, Parra-Blanco A, Beg S, et al. Feasibility and learning curve of unsupervised colorectal endoscopic submucosalhydrodissection at a Western center. Eur J Gastroenterol Hepatol 2020;32(7):804-812

4 Repici A, Hassan C, Pagano N, et al. High efficacy of endoscopic submucosal dissection for rectal laterally spreading tumors larger than $3 \mathrm{~cm}$. Gastrointest Endosc 2013;77(1):96-101 